\title{
Endothelial control of lower limb blood flow in chronic heart failure
}

David C Lindsay, Diana R Holdright, Debbie Clarke, Inder S Anand, Philip A Poole-Wilson, Peter Collins

\begin{abstract}
Background-Limitation of the blood supply to skeletal muscle in chronic heart failure may contribute to the symptoms of fatigue and diminished exercise capacity. The pathophysiology underlying this abnormality is not known. The purpose of this study was to assess the effect of endothelium dependent and independent vasodilator agents on blood flow in the leg of patients with heart failure.
\end{abstract}

Methods and results-Blood flow in the leg was measured in patients with heart failure $(n=20)$ and compared with that in patients with ischaemic heart disease and normal left ventricular function $(n=16)$ and patients with chest pain and normal coronary arteries $(n=8)$. External iliac artery blood flow was measured using intravascular Doppler ultrasound and quantitative angiography. Flow was recorded at rest and in response to bolus doses of the endothelium independent vasodilator, papaverine. Endothelium dependent responses were measured by infusion of acetylcholine and substance $P$. Mean (SEM) baseline blood flow was reduced at rest $(2.9(0.4) v 4.5(0.3) \mathrm{ml} / \mathrm{s}$, $P<0.001)$ and vascular resistance was raised $(37.4(3.6) v 27 \cdot 1(3.0)$ units, $P<$ 0.05 ) in patients with heart failure compared with that in controls. The peak blood flow response to papaverine $(8 \mathrm{mg})$, acetylcholine $\left(10^{-7}-10^{-5} \mathrm{~mol} / \mathrm{l}\right)$, and substance $P$ ( $5 \mathrm{pmol} / \mathrm{min})$ was reduced in heart failure, with greater impairment of the response to acetylcholine than substance $P$. There was a correlation between baseline blood flow in the heart failure group and diuretic dose $(r=-0.62, P=$ 0.003), New York Heart Association classification $(r=-0.65, P=0.002)$, and left ventricular ejection fraction $(r=0 \cdot 80, P=$ 0.0004).

Conclusions-There is reduced blood flow and raised vascular resistance at rest in the legs of patients with heart failure. The degree of impaired blood flow in the leg correlates with the severity of heart failure. There is impairment of the response to both endothelium dependent and independent vasodilators. Abnormal function of the vascular myocyte in heart failure may explain these results as would structural abnormalities of the resistance vessels.

(Heart 1996;75:469-476)
Keywords: endothelium derived relaxing factor; acetylcholine; vasodilatation; congestive heart failure

The commonest symptoms of patients with heart failure are fatigue and shortness of breath. The pathophysiological mechanisms underlying these symptoms are complex, but recent work has emphasised the role of neural and hormonal signals from the periphery. While central haemodynamic variables are important in the genesis of symptoms in acute heart failure, there is poor correlation between the severity of symptoms in chronic heart failure and the left ventricular ejection fraction or pulmonary capillary wedge pressure. ${ }^{1-3}$ Reduction of cardiac output is an important factor limiting exercise capacity when using large groups of muscle, but is unlikely to be a major limiting factor when using small muscle groups. Blood flow to skeletal muscle may increase by 20 -fold with exercise. ${ }^{4}$ This ability to increase limb blood flow with exercise is reduced in patients with chronic heart failure. ${ }^{156}$ Flow limitation in the leg and abnormalities of skeletal muscle ${ }^{7-9}$ could be the substrate for signals giving rise to the characteristic symptoms of heart failure. ${ }^{10}$

The control of limb blood flow is influenced by neural, hormonal, and locally released factors. Endothelium derived relaxing factor (EDRF) contributes to basal peripheral vascular tone in humans in vivo. ${ }^{11}$ Data from animal models $^{12-14}$ and humans ${ }^{15-17}$ suggest that the release of EDRF, or the response to its actions, is impaired in chronic heart failure. Most data from humans are derived from studies of forearm vasculature. ${ }^{518}$ Few studies have reported the blood flow response of the leg ${ }^{515}$ despite activities associated with use of the legs being the commonest cause of symptoms.

The aim of the present study was to compare blood flow in the legs of patients with heart failure and those with normal left ventricular function in response to infusion of the endothelium dependent vasodilators, acetylcholine and substance $P$, and to the endothelium independent agent papaverine. The hypothesis being tested was that the endothelium dependent vasodilator responses of the leg vasculature would be impaired in patients with chronic heart failure.

\section{Patients and methods}

STUDY POPULATION

Patients were recruited from those admitted for routine cardiac catheterisation to the Royal 
Brompton National Heart \& Lung Hospital, London. All were informed of the procedures, and gave their written consent to the study in the presence of an independent witness. The studies were approved by the Ethical Committee of the National Heart \& Chest Hospitals.

Patients aged over 18 years undergoing routine cardiac catheterisation were considered for the study. Patients with unstable angina pectoris, severe coronary artery disease, significant valvar stenosis, peripheral vascular disease, diabetes mellitus, asthma, or systemic hypertension (systolic blood pressure $>160$ $\mathrm{mm} \mathrm{Hg}$ or diastolic blood pressure $>100 \mathrm{~mm}$ $\mathrm{Hg}$ ) were excluded. All vasoactive medication (excluding diuretics, digoxin and angiotensin converting enzyme inhibitors) was stopped for a period of at least $16 \mathrm{~h}$ before the study.

Patients were characterised as having chronic heart failure on the basis of their clinical history, physical findings, use of diuretic treatment, and left ventricular ejection fraction. Patients were divided into two groups: those with heart failure (group A) and those without heart failure (group B). Two groups of patients were studied as controls in group B: patients with atheromatous coronary artery disease and normal left ventricular function and patients with chest pain and angiographically normal coronary arteries. Patients were not included in the latter group if they had evidence of ST segment change with exercise electrocardiography. Those with chest pain and normal coronary arteries were believed to have non-cardiac chest pain with entirely normal hearts, and thus represent a true control group.

The left ventricular ejection fraction was measured from the left ventricular cineangiogram. The severity of heart failure was assessed by the New York Heart Association classification, dosage of diuretic, left ventricular end diastolic pressure. Exercise capacity was measured in some patients as $\mathrm{MVO}_{2}$ with treadmill exercise testing $\left(\mathrm{ml} \mathrm{O}_{2} \cdot \mathrm{kg}^{-1} \cdot \mathrm{min}^{-1}\right)$. The patients with heart failure were subdivided into four groups according to their daily dose of diuretics: no diuretic (group 1); less than or equal to $40 \mathrm{mg}$ frusemide or equivalent (for example, bendrofluazide $5 \mathrm{mg}$ daily) (group 2); greater than $40 \mathrm{mg}$ frusemide to $80 \mathrm{mg}$ frusemide or its equivalent (for example, bumetanide 1-2 mg daily) (group 3); and greater than $80 \mathrm{mg}$ frusemide or equivalent (group 4).

CATHETER LABORATORY PROTOCOL

Cardiac catheterisation was performed using an eight French gauge sheath in situ in the femoral artery and catheterisation of the right heart was undertaken according to clinical indication. Left ventricular and coronary angiograms were performed using non-ionic $x$ ray contrast medium (Omnipaque; Nycomed AS, Oslo, Norway). Sublingual or systemic nitrates were not administered during the study.

Blood flow velocity was measured using a $20 \mathrm{MHz}$ pulsed wave Doppler catheter positioned in the external iliac artery. The catheters were either Schneider (three French gauge Monorail; Schneider, Zurich, Switzerland) or Wessex (5.5 French gauge, Numed, New York, USA) Doppler catheters. Validation studies in the laboratory showed good correlation between recorded and true flows on an experimental test rig in which there was pulsatile circulation of blood in a closed circuit $(r=0.98, \mathrm{P}<0.01)$.

\section{FEMORAL ARTERIAL ANGIOGRAPHY}

Cineangiography of the femoral and external iliac arteries was performed by hand injection of $x$ ray contrast medium $(10 \mathrm{ml})$ and an image was recorded of a radio-opaque calibration marker. The field of view was coned to centre on the external iliac artery and gonadal protection was not used. The external iliac artery diameter was measured at the level of the tip of the catheter using a digital edge detection system (microMipron software; Kontron Elektronik GMBH, Munich, Germany). The artery was assumed to be circular in cross section when calculating vessel area. Sequential angiograms were performed in 22 patients either during, or immediately after administration of each vasoactive agent. Thereafter, the vessel diameter was determined only at the beginning of the study, as it was shown that there were trivial changes of diameter in response to pharmacological interventions (see results).

\section{ADMINISTRATION OF VASODILATOR AGENTS}

Vasoactive drugs were delivered through the infusion port of the Doppler catheter using a syringe pump and were continued for $3.5 \mathrm{~min}$. The transit time of infusate through the catheters was $30 \mathrm{~s}$.

\section{Papaverine}

An ampoule of papaverine $(40 \mathrm{mg}$ ) (Macarthy Medical, Romford, UK) was diluted to $10 \mathrm{ml}$ with sterile water and aliquots were administered by rapid bolus injection. Three doses of papaverine $(4,8$, and $12 \mathrm{mg})$ were administered in a pilot study to 10 or less patients from each group. No significant increment of flow to the increased doses was found, and therefore a bolus of $8 \mathrm{mg}$ was used for all patients in the main study.

\section{Acetylcholine}

The desired final concentrations of acetylcholine in the external iliac artery were $10^{-7}$, $10^{-6}$, and $10^{-5} \mathrm{~mol} / \mathrm{l}$, and the blood flow was assumed to be $200 \mathrm{ml} / \mathrm{min}$ to calculate the required dilutions. Ampoules of acetylcholine $(20 \mathrm{mg})$ (Miochol, CooperVision, Southampton, UK) were diluted serially with $5 \%$ dextrose immediately before the study. Solutions of $2 \times 10^{-3}(0.363 \mathrm{mg} / \mathrm{ml}), 2 \times$ $10^{-4}$, and $2 \times 10^{-5} \mathrm{~mol} / \mathrm{l}$ were prepared and infused at $1 \mathrm{ml} / \mathrm{min}$ for final presumed concentrations of $10^{-5}, 10^{-6}$, and $10^{-7} \mathrm{~mol} / 1$, respectively.

\section{Substance $P$ and control solution}

There are no previous reports of infusion of substance $P$ into the leg. Three doses of sub- 
stance $P(5,10$, and $25 \mathrm{pmol} / \mathrm{min})$ were administered in a pilot study to 10 patients from each group. There was a significant increment of flow to the increased dose of substance $P(P<0.01$ in those without heart failure and $P<0.02$ in patients with heart failure). A dose of $5 \mathrm{pmol} / \mathrm{min}$ was chosen for the main study as this induced a similar response to acetylcholine $10^{-6} \mathrm{~mol} / 1$.

Aliquots of substance $P(0.1 \mathrm{mg})$ were made by dilution of original vials of the peptide (1 mg), (Sigma Chemicals, Poole, UK) in $10 \%$ acetic acid and stored in sterile vials at $-70^{\circ} \mathrm{C}$. The final concentration of substance $P$ was confirmed by radioimmunoassay. Substance $\mathrm{P}$ adheres to plastic, although this binding may be reduced by prior exposure of the plastic to human serum. The final concentration of the elute from the infusion tubing was assayed, and there was found to be no significant difference between the concentration of the eluent from a pretreated or ordinary syringe and tubing. The infusion was therefore made by serial dilution with normal saline $(0.9 \%)$ immediately before the study. Substance $P$ was infused at $1 \mathrm{ml} / \mathrm{min}$ in all cases. Control solutions were made by matched dilution of sterile acetic acid (10\%) in $0.9 \%$ saline.

\section{RECORDING OF BLOOD FLOW AND VASCULAR RESISTANCE IN THE LEG}

The tip of the Doppler probe was manipulated to a position recording the highest velocity and simultaneous recordings were made of the phasic and electronically meaned blood flow velocity. The baseline reading of mean velocity was made after stable readings had been observed for at least $60 \mathrm{~s}$. The response to the papaverine bolus and the infusions was recorded as the maximum level of mean velocity. External iliac artery blood flow was calculated as the product of mean blood flow velocity $\times$ external iliac artery area, assuming blood flow to be linear across the diameter of the vessel. The vascular resistance was calculated as the product of mean blood pressure divided by flow in the leg and reported in arbi-

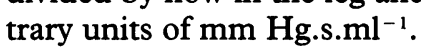

\section{STATISTICAL ANALYSIS}

Data are presented as means (SEM) and were analysed by Student's $t$ test or analysis of variance as appropriate. The level of significance was $\mathrm{P}<0.05$.

Table 1 Clinical characteristics of patients

\begin{tabular}{|c|c|c|c|c|}
\hline & $\begin{array}{l}\text { Patients with } \\
\text { atheromatous } \\
\text { coronary } \\
\text { heart disease } \\
\text { and normal left } \\
\text { ventricular function } \\
(n=16)\end{array}$ & $\begin{array}{l}\text { Patients with } \\
\text { chest pain and } \\
\text { normal coronary } \\
\text { arteries } \\
(n=8)\end{array}$ & $\begin{array}{l}\text { Patients with } \\
\text { heart failure } \\
(n=20)\end{array}$ & $P$ value ${ }^{\star}$ \\
\hline $\begin{array}{l}\text { Age (years) } \\
\text { Ejection fraction (\%) } \\
\text { LVEDP (mm Hg) } \\
\text { Weight (kg) } \\
\text { Arterial pressure (mm Hg) }\end{array}$ & $\begin{array}{l}56 \cdot 9(3 \cdot 0) \\
68(4) \\
11 \cdot 7(4 \cdot 4) \\
76(3 \cdot 7) \\
104(3 \cdot 5)\end{array}$ & $\begin{array}{l}52 \cdot 1(3 \cdot 9) \\
78(2 \cdot 8) \\
13 \cdot 5(4 \cdot 8) \\
83(7 \cdot 1) \\
94(4 \cdot 5)\end{array}$ & $\begin{array}{l}54(2 \cdot 6) \\
35(5 \cdot 4) \\
17 \cdot 2(7 \cdot 1) \\
79(2 \cdot 6) \\
88(4 \cdot 0)\end{array}$ & $\begin{array}{l}\text { NS } \\
<0.0001 \\
<0.02 \\
\text { NS } \\
<0.05\end{array}$ \\
\hline
\end{tabular}

Values are mean (SEM) (ANOVA). ^Patients with versus those without heart failure (i.e. combining patients with atheromatous coronary heart disease and normal left ventricular function and chest pain and normal coronary arteries). LVEDP, left ventricular end diastolic pressure.

\section{Results}

PATIENT CHARACTERISTICS

Three groups of patients were studied: 20 patients with heart failure (16 men), 16 patients with atheromatous coronary heart disease and normal left ventricular function (12 men), and eight patients with chest pain and normal coronary arteries (five men). None of the latter patients had electrocardiographic changes suggestive of myocardial ischaemia with exercise.

Table 1 shows the baseline characteristics of the patient groups. The aetiology of heart failure was idiopathic dilated cardiomyopathy in eight, ischaemic heart disease in nine, and mitral valve disease in three. The mean (SEM) $\mathrm{MVO}_{2}$ was $15 \cdot 6(1 \cdot 2) \mathrm{ml} \mathrm{o} \cdot \mathrm{kg}^{-1} \cdot \mathrm{min}^{-1}(\mathrm{n}=$ 9). Mean blood pressure was not significantly different in the two groups of patients without heart failure, but was significantly lower in those with heart failure than those without ( 88 $(4 \cdot 0) v 99$ (2.9) $\mathrm{mm} \mathrm{Hg}, \mathrm{P}<0.05)$.

Digoxin was taken by 11 patients with heart failure (six with atrial fibrillation) and one each of those with atheromatous coronary heart disease and normal left ventricular function and chest pain and normal coronary arteries, both of whom had atrial fibrillation. Angiotensin converting enzyme inhibitors were taken by 13 patients with heart failure and by none of the other patients. The number of patients with heart failure in each diuretic group was: three (group 1); three (group 2); six (group 3); and eight (group 4). Aspirin was taken by 11 patients with atheromatous coronary heart disease and normal left ventricular function and four with heart failure, but was not used by any of those with chest pain and normal coronary arteries.

VESSEL DIAMETER MEASUREMENTS

In the initial studies the vessel diameter was measured after each pharmacological intervention in eight patients with chest pain and normal coronary arteries, seven with atheromatous coronary heart disease and normal left ventricular function, and seven with heart failure. Analysis of variance showed that there was no significant change of vessel diameter after each intervention except in response to substance $P(5 \mathrm{pmol} / \mathrm{min})$ in patients with chest pain and normal coronary arteries. In the latter patients vessel diameter increased by a

Table 2 Blood flow in the legs of control patients

\begin{tabular}{|c|c|c|}
\hline \multirow[b]{2}{*}{ Intervention } & \multicolumn{2}{|l|}{ Blood flow $(\mathrm{ml} / \mathrm{s})$} \\
\hline & $\begin{array}{l}\text { Patients with } \\
\text { atheromatous } \\
\text { coronary } \\
\text { heart disease } \\
\text { and normal left } \\
\text { ventricular function } \\
(n=16)\end{array}$ & $\begin{array}{l}\text { Patients with } \\
\text { chest pain and } \\
\text { normal coronary } \\
\text { arteries } \\
(n=8)\end{array}$ \\
\hline $\begin{array}{l}\text { Baseline } \\
\text { Papaverine } 8 \mathrm{mg} \\
\text { ACh }\end{array}$ & $\begin{array}{r}4 \cdot 3(0 \cdot 4) \\
12 \cdot 2(1 \cdot 4)\end{array}$ & $\begin{array}{r}5 \cdot 1(0 \cdot 7) \\
13 \cdot 1(1 \cdot 9)\end{array}$ \\
\hline $\begin{array}{l}10^{-7} \mathrm{~mol} / 1 \\
10^{-6} \mathrm{~mol} / 1 \\
10^{-5} \mathrm{~mol} / 1\end{array}$ & $\begin{array}{r}5 \cdot 4(0 \cdot 6) \\
7 \cdot 3(0 \cdot 8) \\
11.3(1 \cdot 8)\end{array}$ & $\begin{array}{r}4.9(1.4) \\
8.6(2 \cdot 0) \\
14.9(4 \cdot 0)\end{array}$ \\
\hline $\begin{array}{c}\text { Substance P } 5 \\
\mathrm{pmol} / \mathrm{min}\end{array}$ & $8 \cdot 7(1 \cdot 2)$ & $8.9(1 \cdot 6)$ \\
\hline
\end{tabular}

Values are mean (SEM). There were no significant differences between control groups. ACh, acetylcholine. 
Figure 1 Absolute blood flow response to administration of each drug (D) and without heart failure $(n=24)(\mathbb{Q})$. Bars are group means (SEM). Base, baseline blood flow; P8, papaverine $8 \mathrm{mg}$. acetylcholine $10^{-7}, 10^{-6}$, and $10^{-5} \mathrm{molll} ;$ SPS, substance $P 5$ pmollmin. $\star P<0.05$ between the two groups ( $t$ test). for patients with $(n=20)$ $A C h 7, A C h 6$, and $A C h 5$,

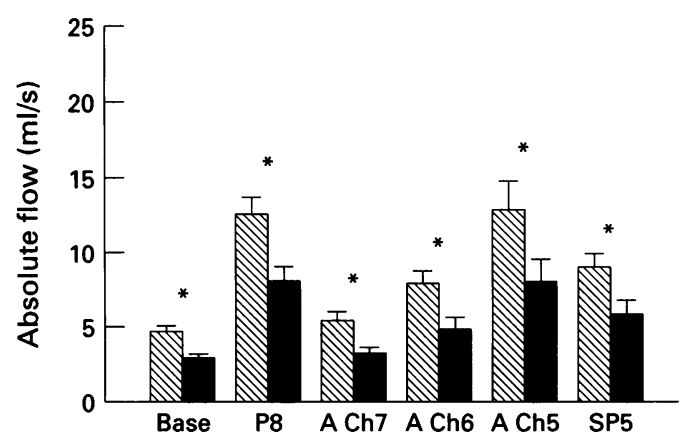

factor of $1.07(0.02)(P=0.002)$. The maximal increase of area (14\%) was deemed inconsequential compared with the increase of flow velocity, which was many times greater, and was thus not measured in each patient or used to calculate flow.

\section{DOPPLER FLOW MEASUREMENTS}

The baseline blood flow and peak blood flow response to papaverine $(8 \mathrm{mg})$, acetylcholine $10^{-7}-10^{-5} \mathrm{~mol} / \mathrm{l}$, and substance $P$ (5 $\mathrm{pmol} / \mathrm{min}$ ) for the control patients are shown in table 2 and are illustrated for those with and without heart failure in fig 1 . There was no correlation between baseline blood flow and body weight $(r=0 \cdot 15)$. Table 3 shows the data derived for the flow ratios (intervention/baseline flow ratio) and incre-

Table 3 Increment of blood flow and ratio of flow in the legs of controls and patients with heart failure

\begin{tabular}{|c|c|c|c|}
\hline Intervention & $\begin{array}{l}\text { Patients without } \\
\text { heart failure } \\
(n=24)\end{array}$ & $\begin{array}{l}\text { Patients with } \\
\text { heart failure } \\
(n=20)\end{array}$ & Pvalue * \\
\hline $\begin{array}{l}\text { Baseline blood flow }(\mathrm{ml} / \mathrm{s}) \\
\text { Increment of flow }(\mathrm{ml} / \mathrm{s})\end{array}$ & $4.5(0.3)$ & $2.9(0.4)$ & $<0.001$ \\
\hline $\begin{array}{l}\text { Papaverine } 8 \mathrm{mg} \\
\text { ACh }\end{array}$ & $8.0(0.8)$ & $5.4(0.8)$ & 0.02 \\
\hline $\begin{array}{c}10^{-7} \mathrm{~mol} / 1 \\
10^{-6} \mathrm{~mol} / 1 \\
10^{-5} \mathrm{~mol} / 1 \\
\text { Substance } P 5 \mathrm{pmol} / \mathrm{min}\end{array}$ & $\begin{array}{l}0 \cdot 7(0 \cdot 2) \\
3 \cdot 3(0 \cdot 7) \\
8 \cdot 2(1 \cdot 6) \\
4 \cdot 2(0 \cdot 7)\end{array}$ & $\left.\begin{array}{l}0 \cdot 3(0 \cdot 2) \\
1 \cdot 9(0 \cdot 6) \\
5 \cdot 4(1 \cdot 3) \\
3 \cdot 1(0 \cdot 6)\end{array}\right\}$ & $\begin{array}{l}<0.05 \dagger \\
\text { NS }\end{array}$ \\
\hline $\begin{array}{l}\text { Ratio of flow } \\
\text { Papaverine } 8 \mathrm{mg} \\
\text { ACh }\end{array}$ & $2 \cdot 7(0 \cdot 1)$ & $3 \cdot 2(0 \cdot 3)$ & NS \\
\hline $\begin{array}{c}10^{-7} \mathrm{~mol} / 1 \\
10^{-6} \mathrm{~mol} / 1 \\
10^{-5} \mathrm{~mol} / 1 \\
\text { Substance } P 5 \mathrm{pmol} / \mathrm{min}\end{array}$ & $\begin{array}{l}1.2(0 \cdot 1) \\
1.8(0 \cdot 2) \\
2.6(0 \cdot 2) \\
1.9(0 \cdot 2)\end{array}$ & $\left.\begin{array}{l}1 \cdot 2(0 \cdot 1) \\
1 \cdot 6(0 \cdot 2) \\
2 \cdot 9(0 \cdot 4) \\
2 \cdot 1(0 \cdot 2)\end{array}\right\}$ & $\begin{array}{l}\text { NS } \\
\text { NS }\end{array}$ \\
\hline
\end{tabular}

Values are mean $(\mathrm{SEM})$. ${ }^{\star}$ Patients with versus those without heart failure (i.e. combining patients with atheromatous coronary heart disease and normal left ventricular function and chest pain and normal coronary arteries). $+\mathrm{P}$ value determined by analysis of variance. ACh, acetylcholine.

Table 4 Vascular resistance in the legs of controls and patients with heart failure

\begin{tabular}{|c|c|c|c|c|c|}
\hline \multirow[b]{2}{*}{ Intervention } & \multicolumn{5}{|c|}{ Resistance ( $m m$ Hg.s.ml-1) } \\
\hline & $\begin{array}{l}\text { Patients with } \\
\text { atheromatous } \\
\text { coronary } \\
\text { heart disease } \\
\text { and normal } \\
\text { left ventricular } \\
\text { function } \\
(n=16)\end{array}$ & $\begin{array}{l}\text { Patients with } \\
\text { chest pain and } \\
\text { normal coronary } \\
\text { arteries } \\
(n=8)\end{array}$ & $\begin{array}{l}\text { Patients without } \\
\text { heart failure } \\
(n=24)^{\star}\end{array}$ & $\begin{array}{l}\text { Patients with } \\
\text { heart failure } \\
(n=20)\end{array}$ & Pvaluet \\
\hline $\begin{array}{l}\text { Baseline } \\
\text { Papaverine } 8 \mathrm{mg} \\
\text { ACh }\end{array}$ & $\begin{array}{l}29.7(3.4) \\
11.0(1.6)\end{array}$ & $\begin{array}{r}22.9(5 \cdot 5) \\
8.9(2 \cdot 1)\end{array}$ & $\begin{array}{l}27 \cdot 1(3 \cdot 0) \\
10 \cdot 1(1 \cdot 3)\end{array}$ & $\begin{array}{l}37 \cdot 4(3 \cdot 6) \\
14 \cdot 4(2 \cdot 1)\end{array}$ & $\begin{array}{l}<0.05 \\
\text { NS }\end{array}$ \\
\hline $\begin{array}{l}10^{-7} \mathrm{~mol} / 1 \\
10^{-6} \mathrm{~mol} / 1 \\
10^{-5} \mathrm{~mol} / 1\end{array}$ & $\begin{array}{l}22.9(2.9) \\
18.9(3.5) \\
14.0(3.0)\end{array}$ & $\begin{array}{l}24.5(7 \cdot 6) \\
15 \cdot 6(4 \cdot 4) \\
10 \cdot 6(3 \cdot 6)\end{array}$ & $\begin{array}{l}22 \cdot 7(3 \cdot 1) \\
17 \cdot 0(2 \cdot 7) \\
12 \cdot 2(2 \cdot 4)\end{array}$ & $\begin{array}{l}33 \cdot 3(3 \cdot 3) \\
29 \cdot 5(4 \cdot 0) \\
17 \cdot 2(2 \cdot 7)\end{array}$ & $\begin{array}{l}<0.05 \\
<0.02 \\
\text { NS }\end{array}$ \\
\hline $\begin{array}{c}\text { Substance P } 5 \\
\mathrm{pmol} / \mathrm{min}\end{array}$ & $14 \cdot 3(2 \cdot 3)$ & $16 \cdot 3(5.9)$ & $15 \cdot 2(3 \cdot 2)$ & $19 \cdot 3(2 \cdot 5)$ & NS \\
\hline
\end{tabular}

Values are mean (SEM) (ANOVA). *Combining patients with atheromatous coronary heart disease and normal left ventricular function and chest pain and normal coronary arteries. †Patients with versus those without heart failure.

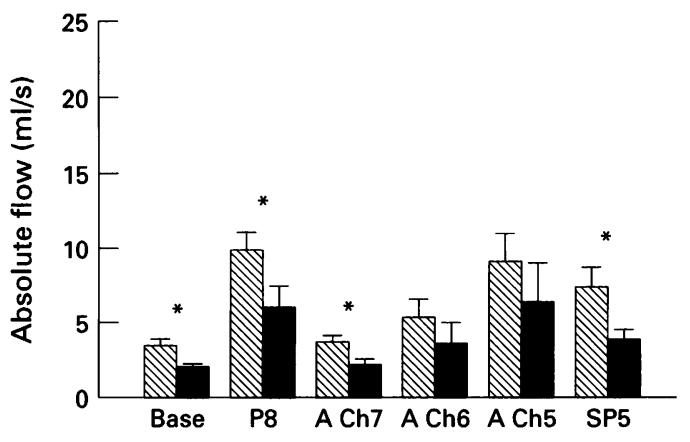

Figure 2 Absolute blood flow response to administration of each drug for patients with heart failure subdivided into "mild" (New York Heart Association (NYHA) I/II, $n=11)$ ( $)$ and "severe" (NYHA III/IV, $n=9)(\square)$ groups. Bars are group means (SEM). Abbreviations as given in fig $1 .{ }^{*} P<0.05$ ( $t$ test).

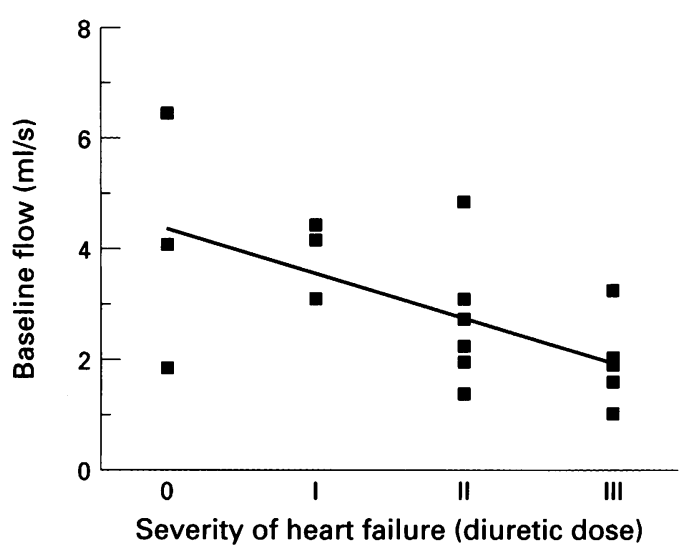

Figure 3 Correlation of baseline blood flow in the leg with diuretic dose in patients with heart failure. Severity of heart failure was assessed by subdivision into patient groups according to diuretic dose (see text). Group I, no diuretic; group II, $\leqslant 40$ mg frusemide; group III, $\leqslant 80 \mathrm{mg}$ frusemide; group $I V,>80 \mathrm{mg}$ frusemide $(r=-0.62, P<0.005)$.

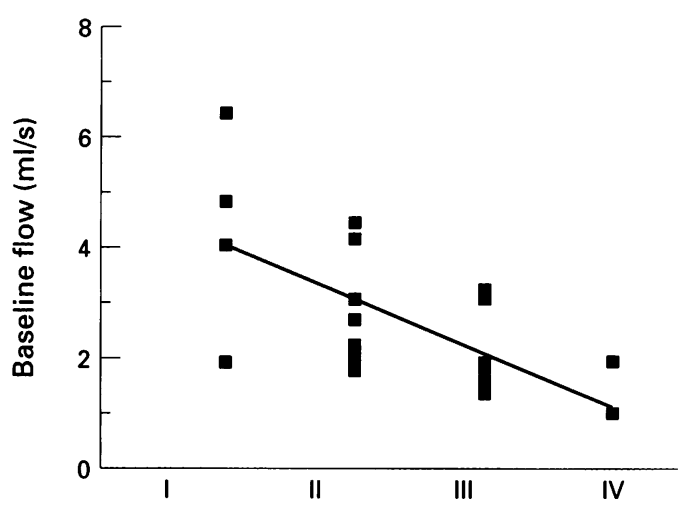

Severity of heart failure (NYHA status)

Figure 4 Correlation of baseline blood flow in the leg with severity of heart failure. Severity of heart failure was assessed by subdivision into patient groups according to the New York Heart Association (NYHA) classification $(r=-0.65, P<0.005)$.

mental changes (intervention flow minus baseline flow) after each infusion. Analysis of variance showed the presence of heart failure to be a significant determinant of the increment of flow response to acetylcholine $(P<0.05)$. There was no change in blood pressure with each intervention. Table 4 shows the derived measures of vascular resistance in the leg in response to pharmacological interventions. The absolute flow to each intervention was reduced in patients with more severe heart 
Figure 5 Correlation of baseline blood flow in the leg with left ventricular ejection fraction ( $L V E F)$ in patients with heart failure $(r=0 \cdot 80, P<$ $0.0005)$. Four patients with symptoms and signs of heart failure but with significant mitral regurgitation were excluded from the analysis because of their spuriously increased LVEF (> 60\%).

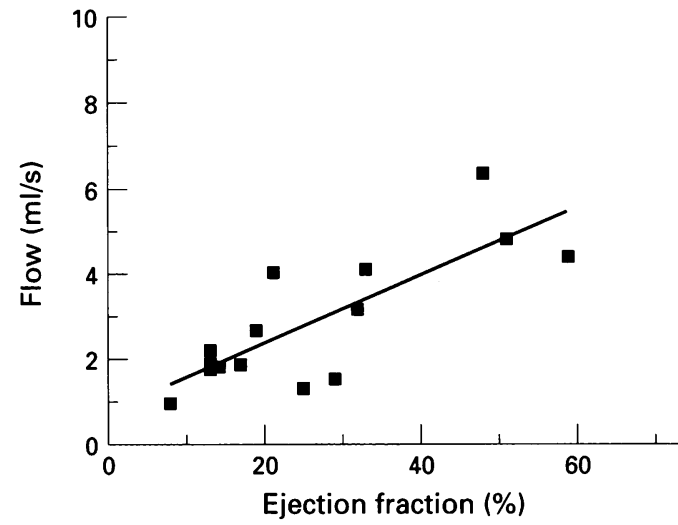

failure (fig 2). There was a correlation between baseline blood flow and diuretic dose (fig 3) $(r=-0.62, \mathrm{P}=0.003)$ and New York Heart Association classification (fig 4) $(r=-0 \cdot 65$, $P=0.002$ ), but not left ventricular end diastolic pressure $(r=0.335, \mathrm{P}=0.168)$ in patients with heart failure. The $\mathrm{MVO}_{2}$ was determined in nine patients with heart failure, but no correlation was found between $\mathrm{MVO}_{2}$ and baseline flow $(r=0.09, \mathrm{P}=0.74)$. There was a correlation between baseline blood flow and left ventricular ejection fraction (fig 5) ( $r=0.80, \mathrm{P}=0.0004$ ) when the four patients with heart failure and significant mitral regurgitation were excluded from the analysis (in each case left ventricular ejection fraction $>60 \%$ ) and no correlation when these patients were included $(r=0 \cdot 32, \mathrm{P}=0 \cdot 18)$.

\section{Discussion}

This study shows that blood flow to the leg is reduced at rest in patients with heart failure compared with that in controls. The absolute flow was reduced in response to administration of papaverine, acetylcholine $10^{-7}-10^{-5}$ $\mathrm{mol} / \mathrm{l}$, and substance $P(5 \mathrm{pmol} / \mathrm{min})$, as was the increment of flow in response to each dose of acetylcholine. There was a significant correlation between the severity of heart failure and absolute flow in response to the vasodilator agents.

The dominant symptoms of heart failure are those of fatigue and breathlessness. These symptoms correlate poorly with simple haemodynamic variables, such as left ventricular ejection fraction and pulmonary capillary wedge pressure,,$^{1-3}$ and abnormalities in the peripheral vasculature in heart failure ${ }^{4619}$ may be important in the genesis of these symptoms. The control of peripheral vascular resistance lies predominantly in the resistance arterioles and is determined by functional or structural changes of the vessel wall, or both. ${ }^{20}$ Vasomotor tone is determined by the effects of neurological stimuli (e.g. the release of norepinephrine and neuropeptides), endocrine stimuli (e.g. angiotensin II or circulating norepinephrine), and locally released paracrine substances, such as endothelium derived relaxing and contracting factors. The sympathetic nervous system is activated in chronic heart failure, although acute administration of adrenergic blocking drugs into the femoral artery does not increase blood flow in the leg. ${ }^{61}$ EDRF has been found to be important in the maintenance of vascular tone in vivo. ${ }^{22} 23$

Our findings are not wholly in agreement with those from other authors. We have shown impairment of the vasodilator response to both endothelium dependent (acetylcholine and substance $P$ ) and independent agents (papaverine) in patients with heart failure, and this impaired flow response correlates with the severity of heart failure. The study of blood flow in the leg, rather than the arm, is of particular relevance as the reduction of exercise induced blood flow in the leg is a limiting factor to exercise capacity in patients with heart failure. ${ }^{6}$ Only one previous study has examined the response of the leg to endothelium dependent and independent vasodilator agents. ${ }^{15}$ This study by Katz et al $^{15}$ assessed blood flow in the leg semiquantitatively by transcutaneous Doppler measurement of flow velocity in the superficial femoral artery. No formal comparison was made of basal flow velocity at rest in controls and patients with heart failure, although it seemed marginally reduced in patients with heart failure. The increase in flow velocity to administration of intra-arterial acetylcholine was significantly reduced, and there was blunting of the response to glyceryl trinitrate.

Other studies of peripheral blood flow to skeletal muscle in heart failure have measured blood flow in the forearm using venous occlusive plethysmography ${ }^{16}$ or transcutaneous Doppler ultrasonography. ${ }^{17}$ In the former study there was significant reduction of methacholine induced vasodilatation, and in the latter of the response to acetylcholine. In contrast to the present study, there was no impairment of the response to endothelium independent actions of nitroprusside or glyceryl trinitrate, respectively. It is not clear whether preservation of response to endothelium independent agents in these two studies reflects differences in vascular tone between the arm and leg, as there may be regional differences of vasomotor control in patients with heart failure. ${ }^{24}$

Maximal vasodilatation cannot be achieved safely in vivo by pharmacological means, and maximum blood flow achieved in these studies is considerably less than may be attained during peak exercise in a normal individual. ${ }^{4}$ Papaverine is probably an endothelium independent vasodilator in vivo in humans and has been shown to be a powerful vasodilator of the coronary circulation. ${ }^{25}$ The drug is administered in bolus form, but its use is limited by the occurrence of arrhythmias at high doses. Many previous investigators have used only acetylcholine or methacholine as endothelium dependent vasodilators. ${ }^{15-17}$ Acetylcholine has vasodilator properties mediated through muscarinic receptor activated release of EDRF and has muscarinic-vasoconstrictor properties through its direct actions on vascular smooth muscle. The vasoconstrictor actions occur at high concentrations of $10^{-6} \mathrm{~mol} / \mathrm{l}$ and above, but altered sensitivity of the muscarinic receptor may exist in heart failure ${ }^{2627}$ and has been 
shown in a dog model of heart failure. ${ }^{28}$ The use of substance $\mathrm{P}$ in these experiments allowed more specific determination of the role of EDRF in the control of vasomotor tone in heart failure. Substance $P$ has a direct effect on the release of EDRF and has no direct effects on vascular smooth muscle. ${ }^{29}$

It is not possible from the present study to determine the mechanisms underlying impaired endothelium dependent responses in heart failure. The study of blood flow in the forearms by Drexler et $a l^{17}$ is of interest as a specific inhibitor of EDRF, $\mathrm{N}^{\mathrm{G}}$-monomethylL-arginine, was infused locally into the brachial artery. Infusion of this inhibitor produced an exaggerated decrease in brachial arterial flow in patients with heart failure, suggesting that basal release of EDRF is preserved or even enhanced in patients with heart failure.

Atherosclerosis of any severity may cause impairment of endothelial function ${ }^{30-32}$ and it was for this reason patients with heart failure of ischaemic and non-ischaemic aetiology and a control group of similar individuals with or without demonstrable atheromatous coronary artery disease were studied. Patients with chest pain, angiographically normal coronary arteries, and ST segment change with exercise electrocardiography (often termed "syndrome X") were excluded, as it has been suggested that these patients may have widespread abnormalities of vasomotor control. ${ }^{33}$ Hypertension, ${ }^{34} 35$ hypercholesterolaemia, ${ }^{36}{ }^{37}$ and diabetes mellitus, ${ }^{38}$ have been implicated in the genesis of vasomotor dysfunction.

There is no optimal method of representing changes of blood flow in such studies. Results are sometimes presented as absolute blood flows, but more often as the increment of increased blood flow above baseline value, the percentage change, or as a ratio of peak flow to baseline blood flow. Such representation can be misleading in assessing the degree of abnormality of vasomotor control if the baseline blood flow is significantly different in the two groups, as was the case in the present study.

Some effects of angiotensin converting enzyme inhibitors, including those on blood flow in the leg, develop over several weeks, ${ }^{39}$ and such actions would not be reversed unless medication was stopped for a lengthy period. The angiotensin converting enzyme inhibitor, captopril, has been reported to increase endothelium dependent vasodilatation in patients with essential hypertension. ${ }^{40}$ Digitalis glycosides may inhibit the release of EDRF and the response of vascular smooth muscle to its actions. ${ }^{41}$ Aspirin was taken by most patients with atheromatous coronary heart disease and normal left ventricular function. The effects of cyclo-oxygenase inhibition on blood flow responses have not been determined fully, although it has been reported that aspirin may reduce the vasodilator properties of the angiotensin converting enzyme inhibitor, enalapril. 42

Blood flow in the external iliac artery in each individual was not known before the investigation, and thus an assumed blood flow of $200 \mathrm{ml} / \mathrm{min}$ was used to calculate the required dilution of each drug. The data from the literature suggest flows of $290-420 \mathrm{ml} / \mathrm{min}$ in normal controls ${ }^{6344}$ and $210-310 \mathrm{ml} / \mathrm{min}$ in patients with heart failure. ${ }^{6435}$ These measurements were made by various techniques, at differing levels in the external iliac or femoral arteries, and in patients with heart failure of varying severity. The flows observed in the present study were within this range, so that the actual drug concentration was close to the expected concentration. The lesser baseline blood flow in the external iliac artery of patients with heart failure will have led to higher concentrations of vasodilator agents and will therefore have underestimated the degree of impairment of vasodilator response.

Increased blood flow may itself cause reflex vasodilatation of the large arteries mediated by the shear stress induced release of EDRF. ${ }^{46}$ The compliance of the brachial artery is reduced in patients with heart failure. ${ }^{18}$ The change of external iliac artery diameter in this study was minimal, and angiograms were therefore not performed after each intervention. The changes in blood flow shown in this study must therefore be the result of changes in the microcirculation.

There was no significant difference in body weight between the controls and patients with heart failure. There was no correlation between body weight and baseline flow in the leg, although no specific measurement of leg or skeletal muscle mass was made. Muscle wasting may occur in patients with heart failure, and a reduction of leg muscle mass might account in part for the reduced blood flow and increased resistance noted in our study.

The cause of increased peripheral vascular resistance in heart failure is not known. The retention of sodium and water in oedematous heart failure may increase vascular tone and diminish vasodilator reserve, possibly through activation of a sodium-calcium exchange mechanism $^{47-49}$ in an endothelium independent manner. Plasma endothelin levels are increased in chronic heart failure, ${ }^{50}$ as are levels of tumour necrosis factor, ${ }^{51}$ and other cytokines, several of which influence vascular tone by endothelium dependent and independent effects. ${ }^{41}$ Furthermore, disturbance of prostaglandin levels has been reported in chronic heart failure and may impair control of vasomotor tone..$^{52}$ The reduced vasodilator response to exercise in heart failure may be due to a reduced response to local metabolites.

\section{LIMITATIONS OF THE STUDY}

Medication, apart from angiotensin converting enzyme inhibitors, digoxin or diuretic treatment, was stopped for at least $16 \mathrm{~h}$ before the study, although the longer term effects of such treatment are not known. The theoretical concerns about changes of external iliac artery diameter in response to increased flow were not supported by our data. The determination of blood flow in patients with atrial fibrillation is problematic, although measurement of mean blood flow minimises any beat to beat variation. The optimum method of displaying 
and comparing flow after administration of vasoactive drugs is not clear, particularly if the baseline flow is different in the groups, as in this study. No significant difference existed when comparing ratios or increments of flow, but it is likely that the absolute flow is the most important physiological determinant.

\section{Conclusions}

This study has shown derangement of vasomotor control in the vasculature of the leg in patients with chronic heart failure. Evidence has been presented for impairment of the response to endothelium dependent (acetylcholine and substance $P$ ) and independent (papaverine) agents. The underlying cause for these abnormalities has not been elicited, although structural factors in the resistance vessels may be important. A correlation has been shown between the severity of the heart failure and impaired blood flow in the leg. These data confirm the importance of peripheral abnormalities in the pathophysiology of chronic heart failure and suggest possible mechanisms for the genesis of symptoms in this condition.

We are indebted to the patients who participated in this study Sister G Maketo, the catheter laboratory staff, P Allibone, S Pearson, and the staff on Paul Wood and York wards at the Pearson, and the staff on Paul Wood and York wards at the
Royal Brompton National Heart \& Lung Hospital without woyal Brompton National Heart \& Lung Hospital without whose help and cooperation this study would not have been
possible. We also thank Dr Ghatei for his assistance in assaying possible. We also thank Dr Ghatei for his assistance in assaying substance P. DCL is supported by a junior research fellowship Myers Squibb cardiovascular fellowship.

1 Sullivan MJ, Knight JD, Higginbotham MB, Cobb FR. Relation between central and peripheral hemodynamics during exercise in patients with chronic heart failure. Muscle blood flow is reduced with maintenance of arteria perfusion pressure. Circulation 1989;80:769-81.

2 Roleau J, Kortas C, Bichet D, de Champlain J. Neurohumoral and hemodynamic changes in congestive heart failure: lack of correlation and evidence of compensatory mechanisms. Am Hearr F 1988;116:746-57.

3 Fink LI, Wilson JR, Ferraro N. Exercise ventilation and pulmonary artery wedge pressure in chronic stable congestive heart failure. Am $\mathcal{f}$ Cardiol 1986;57:249-53.

4 Zelis R, Flaim SF. Alterations in vasomotor tone in congestive heart failure. Prog Cardiovasc Dis 1982;24:437-59.

5 Zelis R, Mason DT, Braunwald E. A comparison of the effects of vasodilator stimuli on peripheral resistance vessels in normal subjects and in patients with congestive heart failure. $f$ Clin Invest 1968;47:960-70.

6 LeJemtel TH, Maskin CS, Lucido D, Chadwick BJ. Failure to augment maximal limb blood flow in response to oneleg versus two-leg exercise in patients with severe heart leg versus two-leg exercise in patie
failure. Circulation 1986;74:245-51.

7 Lipkin DP, Jones DA, Round JM, Poole-Wilson PA. Abnormalities of skeletal muscle in patients with chronic heart failure. Int $f$ Cardiol 1988;18:187-95.

8 Sullivan MJ, Green HJ, Cobb FR Skeletal muscle biochemistry and histology in ambulatory patients with long chemistry and histology in ambulatory patients

9 Mancini DM, Coyle E, Coggan A, et al. Contribution of intrinsic skeletal muscle changes to 31P NMR skeleta muscle metabolic abnormalities in patients with chronic heart failure. Circulation 1989;80:1338-46.

10 Piepoli M, Clark AL, Volterrani M, et al. Muscle ergoreflex role in exertional dyspnea in chronic heart failure patients [abstract]. F Am Coll Cardiol 1993;21:480A.

11 Collier J, Vallance P. Endothelium-derived relaxing factor is an endogenous vasodilator in man. $\mathrm{Br} \mathrm{F}$ Pharmacol 1989;97:639-41.

12 Ontkean M, Gay R, Greenberg B. Diminished endothelium-derived relaxing factor activity in an experimenta model of chronic heart failure. Circ Res 1991;69: 1088-96.

13 Lindsay DC, Jiang C, Brunotte F, et al. Impairment of endothelium dependent responses in a rat model of chronic heart failure: effects of an exercise training protocol. Cardiovasc Res 1992;26:694-7.

14 Drexler H, Hablawetz E, Lu W, Riede U, Christes A Effects of inhibition of nitric oxide formation on regional blood flow in experimental myocardial infarction Circulation 1992;86:255-62.

15 Katz SD, Biasucci L, Sabba C, et al. Impaired endothe- lium-mediated vasodilation in the peripheral vasculature of patients with congestive heart failure. $\mathcal{F} \mathrm{Am}$ Coll Cardiol 1992:19:918-25.

16 Kubo SH, Rector TS, Bank AJ, Williams RE, Heifetz SM. Endothelium-dependent vasodilation is attenuated in patients with heart failure. Circulation 1991;84:1589-96.

17 Drexler H, Hayoz D, Münzel T, et al. Endothelial function in chronic congestive heart failure. Am F Cardiol 1992; 69:1596-601

18 Arnold JMO, Marchiori GE, Imrie JR, Burton GL, Pflugfelder PW, Kostuk WJ. Large artery function in patients with chronic heart failure. Studies of brachial artery diameter and hemodynamics. Circulation 1991; 84:2418-25.

19 Sinoway LI, Minotti JR, Davis D, et al. Delayed reversal of impaired vasodilation in congestive heart failure after heart transplantation. Am $\mathcal{F}$ Cardiol 1988;61:1076-9.

20 Bassenge E, Munzel T. Consideration of conduit and resistance vessels in regulation of blood flow. $\mathrm{Am} F \mathrm{Cardiol}$ $1988 ; 62: 40-4 \mathrm{E}$

21 Leier CV, Binkley PF, Cody RJ. Alpha-adrenergic component of the sympathetic nervous system in congestive heart failure. Circulation 1990;82:168-76.

22 Griffith TM, Edwards DH, Davies RL, Henderson AH. The role of EDRF in flow distribution: a microangiographic study of the rabbit isolated ear. Microvasc Res graphic study of

23 Vallance P, Collier J, Moncada S. Effects of endotheliumderived nitric oxide on peripheral arteriolar tone in man. Lancet 1989;2:997-1000

24 Leier CV. Regional blood flow responses to vasodilators and inotropes in congestive heart failure. $\mathrm{Am} \mathcal{F}$ Cardiol 1988:62:86-93E.

25 Zijlstra F, Serruys PW, Hugenholtz PG. Papaverine: the ideal coronary vasodilator for investigating coronary flow reserve? A study of timing, magnitude, reproducibility, and safety of the coronary hyperaemic response to intracoronary papaverine. Cathet Cardiovasc Diagn 1986;12: 298-303.

26 Hodgson JM, Marshall JJ. Direct vasoconstriction and endothelium-dependent vasodilation. Mechanisms of acetylcholine effects on coronary flow and arterial diameter in patients with nonstenotic coronary arteries. Circulation 1989;79:1043-51.

27 Deighton NM, Zerkowski H, Brodde OE. Muscarinic receptor number and functional responsiveness in patients with mild-to-moderate or end-stage heart failure [abstract]. Eur Heart $\mathcal{f} 1990 ; 11: 71$.

28 Vatner DE, Lee DL, Schwarz KR, et al. Impaired cardiac muscarinic receptor function in dogs with heart failure. $\mathcal{F}$ Clin Invest 1988;81:1836-42.

29 Crossman DC, Larkin SW, Fuller RW, Davies GJ, Maseri A. Substance $P$ dilates epicardial coronary arteries and increases coronary blood flow in humans. Circulation increases coronary

30 Ludmer PL, Selwyn AP, Shook TL, et al. Paradoxical vasoconstriction induced by acetylcholine in atherosclerotic constriction induced by acetylcholine in atheroscle

31 Vita JA, Treasure CB, Nabel EG, et al. Coronary vasomotor response to acetylcholine relates to risk factors for coronary artery disease. Circulation 1990;81:491-7.

32 Werns SW, Walton JA, Hsia HH, Nabal EG, Sanz ML, Pitt B. Evidence of endothelial dysfunction in angiographically normal coronary arteries of patients with coronary artery disease. Circulation 1989;79:287-91.

33 Sax FL, Cannon RO, Hanson C, Epstein SE. Impaired forearm vasodilator reserve in patients with microvascular angina. $N$ Engl $\mathcal{F}$ Med 1987;317:1366-70.

34 Linder L, Kiowski W, Bühler FR, Luscher TF. Indirect evidence for release of endothelium-derived relaxing factor in human forearm circulation in vivo. Blunted response in essential hypertension. Circulation 1990;81:1762-7.

35 Luscher TF, Yang Z, Diederich D, Bühler FR. Endothelium-derived vasoactive substances: potential role in hypertension, atherosclerosis, and vascular occlusion. $\mathcal{F}$ Cardiovasc Pharmacol 1989;14(suppl 6): S63-9.

36 Wright CE, Angus JA. Effects of hypertension and hypercholesterolemia on vasodilatation in the rabbit. Hypertension 1986;8:361-71.

37 Creager MA, Cooke JP, Mendelsohn ME, et al. Impaired vasodilation of forearm resistance vessels in hypercholesterolemic humans. $\mathcal{F}$ Clin Invest 1990;86:228-34.

38 Mayhan WG. Impairment of endothelium-dependent dilation of arterioles during diabetes mellitus. Am F Physiol tion of arterioles durit
1989;256:H621-5.

39 Drexler H, Banhardt U, Meinertz T, Wollschlager $\mathrm{H}$, Lehmann $M$, Just $H$. Contrasting peripheral short-term and long-term effects of converting enzyme inhibition in patients with congestive heart failure. A double-blin

40 Hirooka Y, Imaizumi T, Takeshita A, Ando S, Haroda S. Impaired endothelial-dependent forearm vasodilation to acetylcholine in patients with essential hypertension and effects of captopril [abstract]. Circulation 1990;82 (suppl III):III-346.

41 Vanhoutte PM. Endothelial-derived relaxing and contracting factors. Heart Failure 1989;5:5-12.

42 Hall D, Zeitler H, Rudolph W. Counteraction of the vasodilator effects of enalapril by aspirin in severe hear failure. F Am Coll Cardiol 1992;20:1549-55.

43 Wilson JR, Martin JL, Ferraro N, Weber KT. Effect of hydralazine on perfusion and metabolism in the leg during upright bicycle exercise in patients with heart failure. Circulation 1983;68:425-32. 
44 Jorfeldt L, Wahren J. Leg blood flow during exercise in man. Clin Sci 1971;41:459-73.

45 Wilson JR, Ferraro N, Wiener DH. Effect of the sympathetic nervous system on limb circulation and metabolism during exercise in patients with heart failure. Circulation 1985;72:72-81.

46 Rubanyi GM, Romero JC, Vanhoutte PM. Flow-induced release of endothelium-derived relaxing factor. $\mathrm{Am} \mathscr{J}$ Physiol 1986;250:H1145-9.

47 Zelis R, Mason DT. Diminished forearm arteriolar dilator capacity produced by mineralocorticoid-induced salt retention in man. Implications concerning congestive heart failure and vascular stiffness. Circulation 1970;41: 589-92

48 Zelis R, Delea CS, Coleman HN, Mason DT. Arterial sodium content in experimental congestive heart failure. Circulation 1970;41:213-6.
49 Zelis R, Lee G, Mason DT. Influence of experimental edema on metabolically determined blood flow. Circ Res edema on metab

50 McMurray JJ, Ray SG, Abdullah I, Dargie HJ, Morton JJ. Plasma endothelin in chronic heart failure. Circulation 1992;85:1374-9.

51 Levine B, Kalman J, Mayer L, Fillit HM, Packer M. Elevated circulating levels of tumor necrosis factor in severe chronic heart failure. $N$ Engl f Med 1990;323: 236-41.

52 Kaiser L, Spickard RC, Olivier NB. Heart failure depresses endothelium-dependent responses in canine femoral artery. Am F Physiol 1989;256:H962-7.

53 Dzau VJ, Swartz SL. Dissociation of the prostaglandin and renin angiotensin systems during captopril therapy for chronic congestive heart failure secondary to coronary artery disease. Am f Cardiol 1987;60:1101-5.

\section{ABSTRACTS IN CARDIOLOGY}

\section{Need you biopsy for acute myocarditis?}

The Mason trial of treating acute myocarditis has appeared. One of the most significant results is that at most $10 \%$ of subjects with clinically suspected acute myocarditis will have a positive tissue confirmation. Because a positive tissue diagnosis was an entry criteria the trial turned out rather smaller than hoped.

Nevertheless there is nothing to suggest that immunosuppression is beneficial. The implication is that cardiac biopsy if carried out with the sole aim of establishing a diagnosis to aid treatment is not a useful procedure. Numerous questions remain. What disease is present and what is the prognosis of those patients with a negative biopsy?

M J DAVIES

\section{A clinical trial of immunosuppressive therapy for myocarditis}

fay W Mason, fohn B O'Connell, Ahvie Herskowitz, Noel $R$ Rose, Bruce M McManus, Margaret E Billingham, Thomas E Moon, The Myocarditis Treatment Trial Investigators

Background-Myocarditis is a serious disorder, and treatment options are limited. This trial was designed to determine whether immunosuppressive therapy improves left ventricular function in patients with myocarditis.

Methods-We randomly assigned 111 patients with a histopathological diagnosis of myocarditis and a left ventricular ejection fraction of less than 0.45 to receive conventional therapy alone or combined with a 24-week regimen of immunosuppressive therapy. Immunosuppressive therapy consisted of prednisone with either cyclosporine or azathioprine. The primary outcome measure was a change in the left ventricular ejection fraction at 28 weeks.

Results-In the group as a whole, the mean ( \pm SE) left ventricular ejection fraction improved from $0.25 \pm 0.01$ at base line to $0.34 \pm 0.02$ at 28 weeks $(P<0.001)$. The mean change in the left ventricular ejection fraction at 28 weeks did not differ significantly between the group of patients who received immunosuppressive therapy (a gain of $0.10 ; 95$ percent confidence interval, 0.07 to 0.12 ) and the control group (a gain of $0.07 ; 95$ percent confidence interval, 0.03 to $0 \cdot 12$ ). A higher left ventricular ejection fraction at base line, less intensive conventional drug therapy at base line, and a shorter duration of disease, but not the treatment assignment, were positive independent predictors of the left ventricular ejection fraction at week 28 . There was no significant difference in survival between the two groups $(P=0.96)$. The mortality rate for the entire group was 20 percent at 1 year and 56 percent at $4 \cdot 3$ years. Features suggesting an effective inflammatory response were associated with less severe initial disease.

Conclusions-Our results do not support routine treatment of myocarditis with immunosuppressive drugs. Ventricular function improved regardless of whether patients received immunosuppressive therapy, but long-term mortality was high. ( $N$ Engl $\mathcal{f}$ Med 1995;333:269-75.) 